\title{
Characterisation of a subaqueously deposited silt iron ore tailings
}

\author{
D. REID*, R. FANNI $\dagger, \mathrm{K} . \mathrm{KOH} \dagger$ and I. OREA $\dagger$
}

\begin{abstract}
A geotechnical investigation was carried out to characterise a subaqueously deposited, primarily silt, iron ore tailings. Piezocone penetration tests (CPTu) were carried out followed by piston tube sampling at a selected target depth. Piston samples provided measures of in situ density (by means of gravimetric water content), and supplied material for reconstituted and intact laboratory testing. Reconstituted samples prepared using moist tamping (MT) for determination of the critical state locus (CSL), along with intact specimens, were both tested. The potential existence of layering within the recovered specimens was also assessed, indicating near-homogenous samples. The laboratory testing of intact specimens suggested that they appeared to tend towards the same CSL as that obtained from reconstituted loose MT specimens. This tentative result differs from some previous comparisons - with the agreement seen in this case being suggested to primarily result from a lack of layering. In situ state as inferred from both CPTu data and comparison of tube densities to the CSL suggested a loose state.
\end{abstract}

KEYWORDS: in situ testing; laboratory tests; silts

ICE Publishing: all rights reserved

\section{INTRODUCTION}

Silts present unique geotechnical characterisation challenges (Shuttle \& Jefferies, 2016), as (a) they may suffer significant disturbance when sampled, (b) methods developed for clays to correct for sample disturbance may be inapplicable, (c) there is a paucity of calibration chamber to assist in piezocone penetration test $(\mathrm{CPTu})$ interpretation and $(\mathrm{d})$ reconstituted samples may not provide a reasonable proxy for in situ material fabric and shear behaviour (Høeg et al., 2000; Chang et al., 2011). Further, many tailings deposits - which are likely the largest structures currently created by humans (Robertson, 2011), and suffer from a poor safety record (Davies, 2002) comprise primarily silt-sized particles.

Of the challenged previously listed, perhaps the most fundamental is the difference frequently seen between reconstituted and intact specimens of silty tailings (Høeg et al., 2000; Chang et al., 2011). While differences in in situ and reconstituted fabric would be expected to have an effect at low strains (Shuttle, 2006), the work of Høeg et al. and Chang et al. show fabric effects extending to high strains - of such a magnitude that a unique critical state locus (CSL) appears implausible. The reasons for these observations are currently unclear. They may include layering - which was noted by Høeg et al. for their samples, and appears to be visually evident in the block samples used by Chang et al. (Chang, 2009). The potential significant differences exhibited by layered and reconstituted samples were outlined by Baziar \& Dobry (1995). More recently, differences in pore fluid chemistry has been speculated as another potential cause for the differences seen in intact and reconstituted specimens (Jamiolkowski, 2014).

This study presents the results of the geotechnical investigation and laboratory testing of a subaqueously deposited

Manuscript received 13 June 2018; first decision 8 October 2018; accepted 9 October 2018.

Published online at www.geotechniqueletters.com on 12 December 2018.

*Department of Civil, Environmental, and Mining Engineering, University of Western Australia, Crawley, WA, Australia. †Golder Associates Pty Ltd. silty iron ore tailings, where the results enable assessment of a number of the previously discussed challenges related to silt characterisation. Initial assessment was based on CPTu-based screening techniques, with four tube samples then obtained from a selected target depth adjacent to a CPTu, followed by reconstituted and intact testing. This work includes efforts to assess the uniqueness of the CSL between reconstituted and intact samples, and assessing the existence of layering in situ.

\section{GEOTECHNICAL INVESTIGATION \\ Site description}

The site is an iron ore tailings deposit located in Australia. The tailings are non-plastic, predominantly silt-sized, and are deposited at a slurry density that minimises segregation. While deposition is subaerial within the majority of the tailings storage facility (TSF), in an isolated zone near the perimeter embankment deposition occurred subaqueously due to difficulties managing the supernatant pond. The tailings depth in this area was approximately $9 \mathrm{~m}$ at the time of the investigation. A thin surface crust of dried tailings was sufficient to enable access by a tracked CPTu rig. As there is evidence that subaqueously deposited silts may result in a looser in situ state compared with subaerially deposited materials (e.g. Reid \& Jefferies, 2017), emphasis was placed on the area of historic subaqueous deposition.

\section{CPTu data}

The results of CPTu 1, located within the subaqueously deposited tailings, are presented in Fig. 1 as normalised tip resistance $(Q)$, friction ratio $\left(F_{\mathrm{r}}\right)$, pore-pressure response $\left(u_{2}\right)$ and equilibrium pore pressure $\left(u_{0}\right)$. In addition, a screeninglevel estimate of state parameter $(\psi)$ (Been \& Jefferies, 1985) based on the method outlined by Plewes et al. (1992) - likely the most commonly applied $\psi$ screening method used currently in silt tailings is shown (Shelbourn, 2010; Jefferies \& Been, 2015; Morgenstern et al., 2016). Below a dense crust, the CPTu results through the subaqueously deposited tailings are contractive, with $\psi$ ranging from $0 \cdot 05$ to $0 \cdot 15$. 


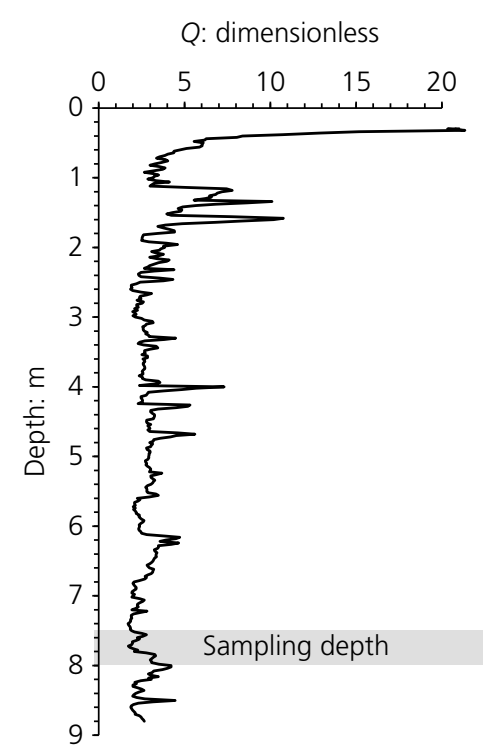

(a)
$F_{\mathrm{r}}: \%$

$u_{2}$ or $u_{0}: \mathrm{kPa}$

$\psi$ : dimensionless

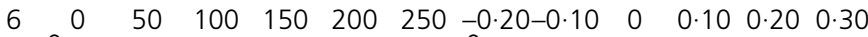

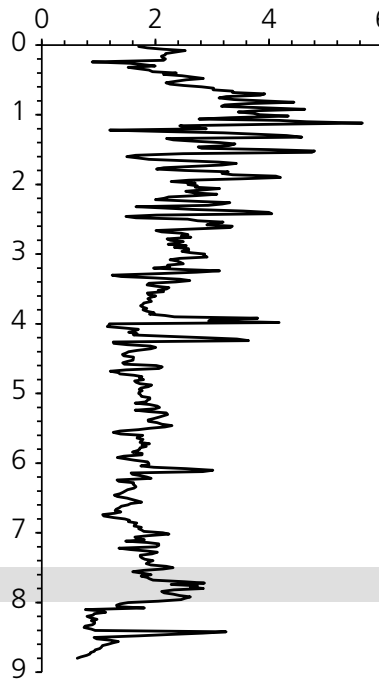

(b)

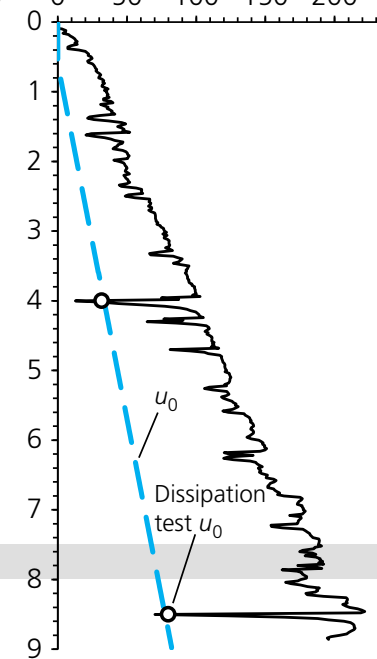

(c)

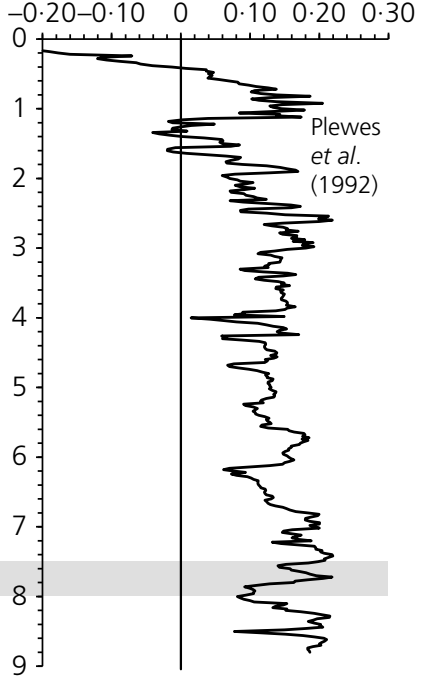

(d)

Fig. 1. CPTu results: (a) normalised tip resistance $(Q)$; (b) friction ratio $\left(F_{r}\right)$; (c) pore-pressure response $\left(u_{2}\right)$ and equilibrium pore pressure $\left(u_{0}\right) ;(d)$ state parameter $(\psi)$

\section{Sampling}

On the basis of the CPTu 1 results, a target sampling depth of 7.6-8.0 $\mathrm{m}$ was selected. A CPTu piston tube sampler was then used to collect four $60 \mathrm{~mm}$ diameter stainless-steel tube samples from within approximately $3 \mathrm{~m}$ of $\mathrm{CPTu} 1$. These samples form the basis of subsequent laboratory testing. Owing to the lack of plasticity of the tailings, and significant driving distance to the laboratory $(>1000 \mathrm{~km})$, the samples were expected to be of low quality. Care was taken to ensure that the tubes were well sealed such that they would not leak during transport.

\section{LABORATORY TESTING \\ Sample management and preparation}

After arrival of the tube samples in the laboratory, two tubes (tubes 1 and 2) were extruded in their entirety into drying trays. As an appreciable quantity of free water was evident above the sample within the tubes (consistent with a disturbed sample), care was taken to ensure all solids and water from the tubes were captured in the drying trays. Gravimetric water content (GWC) of tubes 1 and 2 was then measured by first drying the entire sample in a cool oven $\left(\sim 50^{\circ} \mathrm{C}\right)$, then thoroughly mixing the near-dry sample and taking a small sub-sample for further drying in a hot oven $\left(\sim 105^{\circ} \mathrm{C}\right)$. Recording mass losses from both initial cool oven drying and the sub-sample in the hot oven throughout this process enabled GWC of the original tubes to be obtained without drying the majority of the specimen in a hot oven which could result in changes to mechanical behaviour, including potentially the CSL (Riemer \& Seed, 1997). The material from the two tubes was then combined to create a single composite sample for preparing reconstituted specimens. The index properties for this composite sample are presented in Table 1. The remaining two tubes (tubes 3 and 4) were stored such that their subsequent usage could be informed by results of the initial reconstituted testing.

\section{Testing methods}

Strength testing on the sampled tailings consisted of triaxial and direct simple shear (DSS) tests. All reconstituted tests utilised the moist tamping (MT) preparation method.
Table 1. Index properties of bulk sample

\begin{tabular}{l|l|l|c}
\hline Property & Test type & Unit & Value \\
\hline$G_{\mathrm{s}}$ & Helium pycnometry & Dimensionless & $2 \cdot 78$ \\
$\%<75 \mu \mathrm{m}$ & Wet sieving & $\%$ & 88 \\
$\%<38 \mu \mathrm{m}$ & Wet sieving & $\%$ & 77 \\
& Sedigraph & $\%$ & 78 \\
$D_{10}$ & Sedigraph & $\mu \mathrm{m}$ & 1 \\
\hline
\end{tabular}

Triaxial tests were prepared in eight layers using the undercompaction method (Ladd, 1978). Triaxial tests included oversized, lubricated end platens, with soil freezing used at end of test to improve void ratio measurement. Samples had approximate initial dimensions of $126 \mathrm{~mm}$ high and $63 \mathrm{~mm}$ diameter. Drained tests were consolidated isotropically, while undrained tests were consolidated either under $K_{0}$ conditions (based on average sample area and volume change) or under anisotropic conditions to a specific $K_{0}$ value. Anisotropic conditions were used to improve estimates on in situ undrained strengths and brittleness, although use of such initial conditions was not required for the particular scope of this paper. All MT triaxial tests were prepared loose, except for one dense test carried out to provide state dilatancy data. Triaxial tests carried out are summarised in Table 2.

DSS tests were carried out under constant-volume conditions, with lateral restraint provided by a membrane surrounded by Teflon-coated rings. DSS samples were $60 \mathrm{~mm}$ in diameter and approximately $20 \mathrm{~mm}$ high. DSS tests carried out are summarised in Table 3. All reconstituted DSS tests were prepared loose using the MT technique in a single layer.

After completion of reconstituted testing, intact specimens from tubes 3 and 4 were extruded directly into membrane-lined split moulds, and trimmed to the appropriate height - a sample preparation method referred to herein as 'intact'. Although these intact samples were of poor quality, they can still provide an indication as to whether they tend towards the same CSL as that obtained from MT specimens. Indeed, one of the most prominent studies comparing intact and reconstituted samples was based on low plasticity silt materials likely to be disturbed 
Table 2. Triaxial test summary

\begin{tabular}{|c|c|c|c|c|c|c|c|c|c|}
\hline Test & $\begin{array}{l}\text { Preparation } \\
\text { method }\end{array}$ & $\begin{array}{l}\text { Test } \\
\text { type }\end{array}$ & $p_{\mathrm{c}}^{\prime}: \mathrm{kPa}$ & $q_{\mathrm{c}}: \mathrm{kPa}$ & $K_{0}:$ dimensionless & $e_{\mathrm{c}}:$ dimensionless & $p_{\mathrm{cs}}^{\prime}: \mathrm{kPa}$ & $q_{\mathrm{cs}}: \mathrm{kPa}$ & $e_{\mathrm{cs}}:$ dimensionless \\
\hline TX-01 & MT & $\mathrm{C} K_{0} \mathrm{U}$ & 699 & 596 & $0 \cdot 46$ & 0.643 & 514 & 691 & 0.643 \\
\hline TX-02 & MT & CID & 501 & 3 & 0.99 & 0.692 & 1027 & 1577 & 0.611 \\
\hline TX-03 & MT & $\mathrm{C} K_{0} \mathrm{U}$ & 94 & 57 & $0 \cdot 57$ & 0.747 & 47 & 66 & $0 \cdot 747$ \\
\hline TX-04 & MT & CAU & 224 & 161 & $0 \cdot 51$ & 0.709 & 136 & 218 & 0.709 \\
\hline TX-05 & MT & CID & 300 & 4 & 0.99 & 0.538 & - & - & - \\
\hline TX-06 & Intact & CID & 701 & 3 & $1 \cdot 00$ & 0.525 & - & - & - \\
\hline TX-07 & Intact & $\mathrm{C} K_{0} \mathrm{U}$ & 436 & 452 & $0 \cdot 39$ & 0.597 & 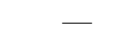 & 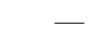 & - \\
\hline
\end{tabular}

Table 3. DSS test summary

\begin{tabular}{|c|c|c|c|c|c|}
\hline Test & Preparation method & $\sigma_{\mathrm{vc}}^{\prime}: \mathrm{kPa}$ & $e_{\mathrm{c}}:$ dimensionless & Peak $s_{\mathrm{u}}: \mathrm{kPa}$ & $s_{\mathrm{u}} / \sigma_{\mathrm{vc}}^{\prime}:$ dimensionless \\
\hline $\begin{array}{l}\text { DSS-1 } \\
\text { DSS-2 } \\
\text { DSS-3 } \\
\text { DSS-4 } \\
\text { DSS-5 } \\
\text { DSS-6 }\end{array}$ & $\begin{array}{l}\text { MT } \\
\text { MT } \\
\text { MT } \\
\text { Intact } \\
\text { Intact } \\
\text { Intact }\end{array}$ & $\begin{array}{l}500 \\
250 \\
150 \\
150 \\
300 \\
600\end{array}$ & $\begin{array}{l}0.674 \\
0 \cdot 714 \\
0 \cdot 672 \\
0 \cdot 611 \\
0 \cdot 566 \\
0.544\end{array}$ & $\begin{array}{c}79 \\
39 \\
42 \\
88^{*} \\
140 \\
215\end{array}$ & $\begin{array}{l}0 \cdot 16 \\
0 \cdot 16 \\
0 \cdot 28 \\
0 \cdot 59 * \\
0 \cdot 47 \\
0 \cdot 36\end{array}$ \\
\hline
\end{tabular}

*Sample still dilating at $22 \%$ strain

due to sampling procedures and transport (Høeg et al., 2000).

Tube 3 was used for monotonic and cyclic DSS samples of which only the two monotonic tests are discussed in detail herein. Tube 4 was used to obtain sample for two triaxial tests. Monotonic DSS tests were carried out at vertical effective stresses of 500 and $1000 \mathrm{kPa}$ to assess the potential for higher stresses to affect undrained strength ratios and contractive or dilative response. The intact triaxial tests were consolidated higher stresses than in situ conditions in an attempt to produce less-dilative specimens that might have measurable critical state conditions.

After testing, the oven-dried intact specimens were all wet sieved through 75 and $38 \mu \mathrm{m}$ sieves, to provide an indication on in situ layering. DSS tests were sieved as a single sample, while triaxials were split into three specimens of approximate equal length (top, middle, bottom).

\section{Triaxial test results}

Triaxial test results are presented in Fig. 2, and as a state diagram in Fig. 3. MT samples prepared loose exhibited contractive behaviour, with the tests reaching constant (or minimally changing) mean effective stress, deviator stress and volume change or shear-induced pore pressure with continuing strain and without visually apparent localisation. These tests allowed identification of a consistent CSL as outlined in Fig. 3. Intact specimens and the single dense MT sample exhibited dilative conditions - a behaviour consistent with their initial denser state compared with the CSL obtained from MT specimens - although they did not reach the MT CSL. This is not an unusual outcome for dense samples. For example, dilative samples are more likely to exhibit shear localisation (Desrues et al., 1996), with the shear band void ratio impractical to obtain using standard procedures. Therefore, it is not necessarily evident of a non-unique CSL if a dense specimen does not reach the CSL obtained from loose specimens. Further, a 'flattening' of the rate of change of volumetric strain, as measured on the entire specimen, does not necessarily suggest critical state conditions have been reached for the entire specimen, should shearing be occurring preferentially on a shear band. It is noted that in both of the intact tests and the dense MT tests, a shear band was visually evident. Further, in addition to potential localisation effects, dilative specimens may not achieve critical state conditions within the strain limits of the triaxial device (Been et al., 1992, Jefferies \& Been, 2015) regardless of specimen homogeneity considerations.

Although the intact specimens did not reach the CSL, examination of the drained intact sample in a state-dilatancy framework can provide a first indication as to whether the CSL from loose MT specimens may be relevant to the intact specimens. This process is outlined in Fig. 4, along with the results of the dense MT test. These two results are seen to have reasonable agreement in this context, lying on the same trend. The interpretation presented in Fig. 4 emphasises that $\psi$ has been calculated based on the CSL from MT specimens. Therefore, the similar trend suggested by both tests provides a tentative indication that the CSL from MT testing is applicable to intact materials. Further, the stress-dilatancy $(\chi)$ value of $5 \cdot 0$ suggested by the data from the two specimens is consistent with many silty tailings materials (Jefferies \& Been, 2015).

\section{DSS test results}

The results of DSS testing are presented in Fig. 5. Intact specimens were initially contractive, with subsequent phase transformation to dilation at higher strains. MT samples, which were at looser states than the intact specimens, were contractive giving undrained strength ratios $\left(s_{\mathrm{u}} / \sigma_{\mathrm{vc}}^{\prime}\right)$ of $0 \cdot 16-0 \cdot 28$

The undrained strength ratio from each DSS test is presented in Fig. 6, where test initial state $\left(\psi_{0}\right)$ is plotted against $s_{\mathrm{u}} / \sigma_{\mathrm{vc}}^{\prime}$. For the purposes of plotting the results, mean effective stress, and hence $\psi_{0}$, was calculated based on a range of likely plausible $K_{0}$ values from 0.4 to 0.6 . The general trend of $s_{\mathrm{u}} / \sigma_{\mathrm{vc}}^{\prime}$ to $\psi_{0}$ is consistent between the MT and intact DSS tests - again, potentially indicative of a single CSL relevant for both in situ and reconstituted fabrics.

\section{Gradation with depth}

The results of wet sieving on each intact specimen are outlined in Fig. 7 against depths inferred from their location within the sample tubes. Also compared is the gradation of 


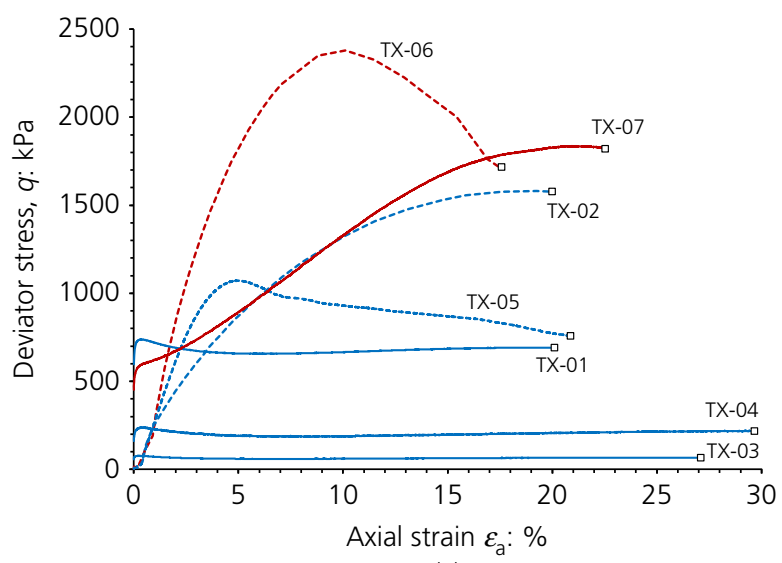

(a)

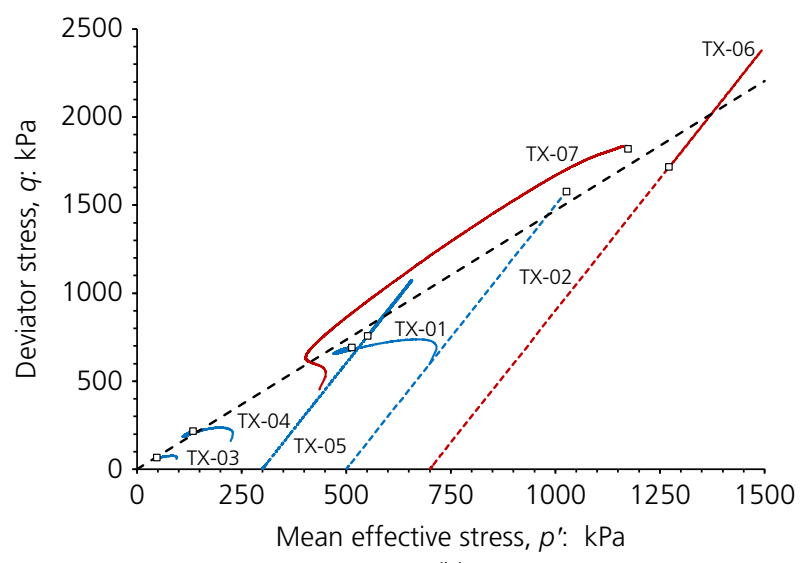

(b)

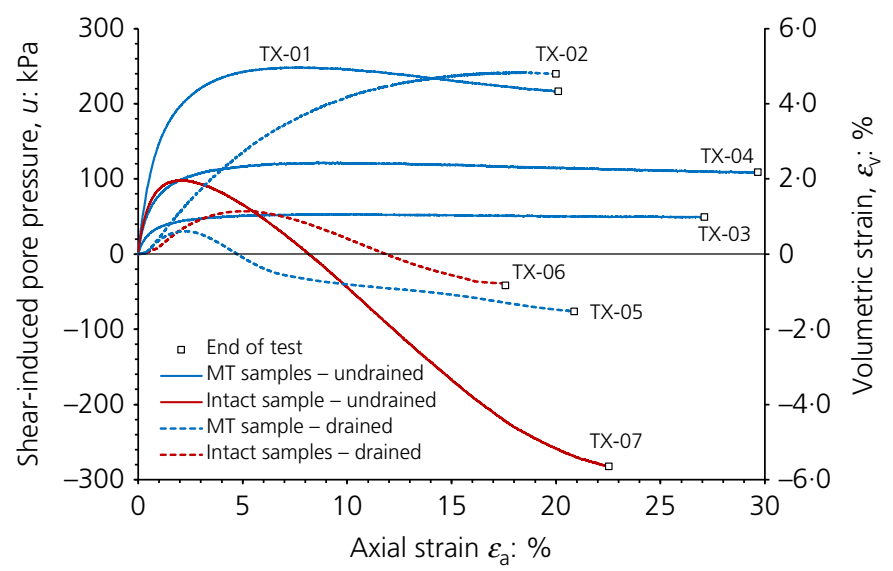

(c)

Fig. 2. Triaxial test results, (a) stress-strain, (b) deviator plotted against mean effective stress, (c) volumetric strain and shear-induced pore pressure

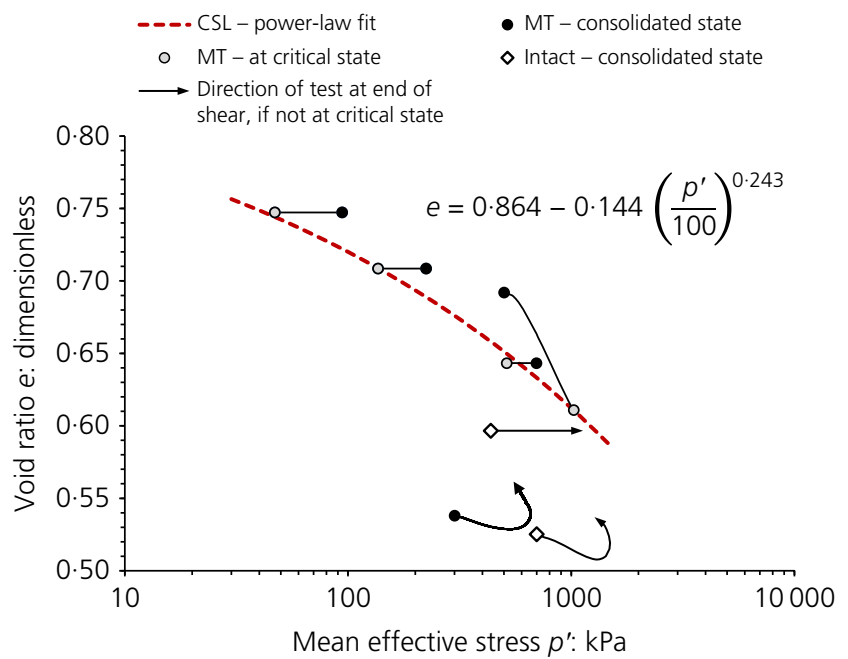

Fig. 3. Triaxial testing and CSL state diagram

the bulk sample prepared from tubes 1 and 2 in their entirety. The differences seen are minimal - indeed, they are far less than those measured in many tailings, including deposits that have been tested for the purposes of comparing intact and reconstituted samples (Høeg et al., 2000; Jamiolkowski, 2014). This suggests that in situ layering was unlikely to have had a significant effect on the behaviour of intact specimens, and assists in their comparison to reconstituted samples that is, all sample tests are relatively uniform, and have the same approximate gradation.

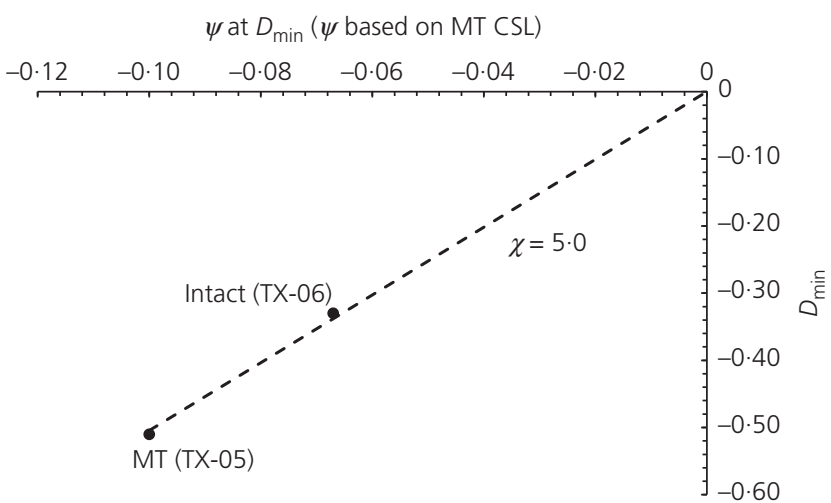

Fig. 4. State-dilatancy relationship for dense samples

\section{SYNTHESIS OF CPTU AND LABORATORY DATA}

The inferred state from CPTu (Plewes et al., 1992) and void ratio calculated from tube GWC are shown in comparison with a number of the laboratory test densities in Fig. 8. Good agreement between the CPTu-inferred states and that obtained from tube sample void ratios is indicated. The significant densification of the laboratory-tested intact samples through sampling, transport and extrusion is evident. Clearly, reliance on intact samples to provide strength inputs would be unsafe regardless of the consolidation stress selected for laboratory testing with this magnitude of disturbance.

Perhaps, the most important observation from the data synthesis in Fig. 8 is the looser state in situ compared with MT samples prepared as loose as practicable in the 


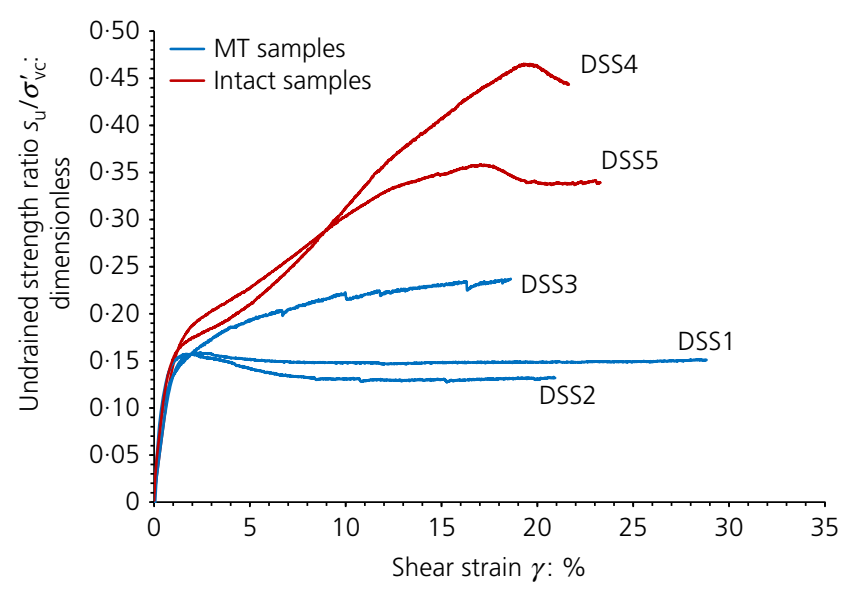

(a)

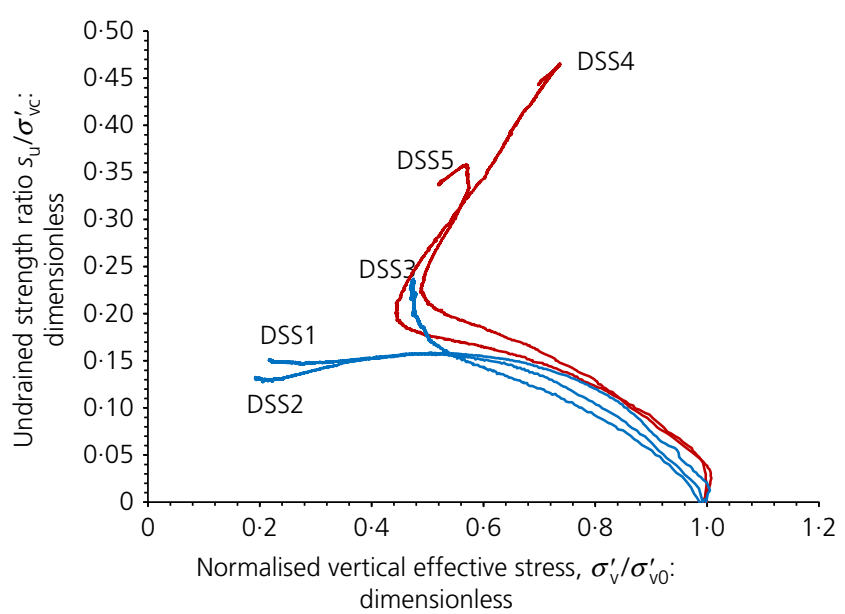

(b)

Fig. 5. DSS test results: (a) stress-strain; (b) normalised vertical effective stress - undrained shear strength

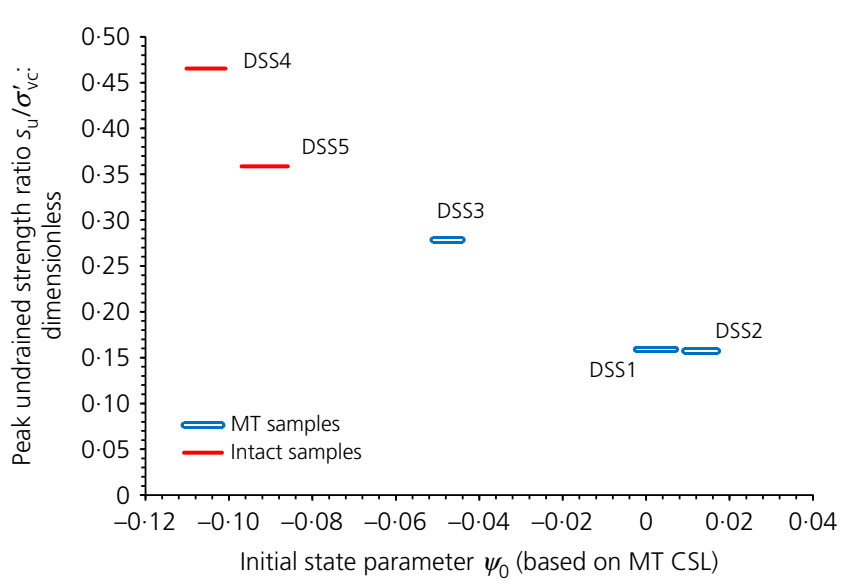

Fig. 6. Peak undrained strength ratio plotted against state summary

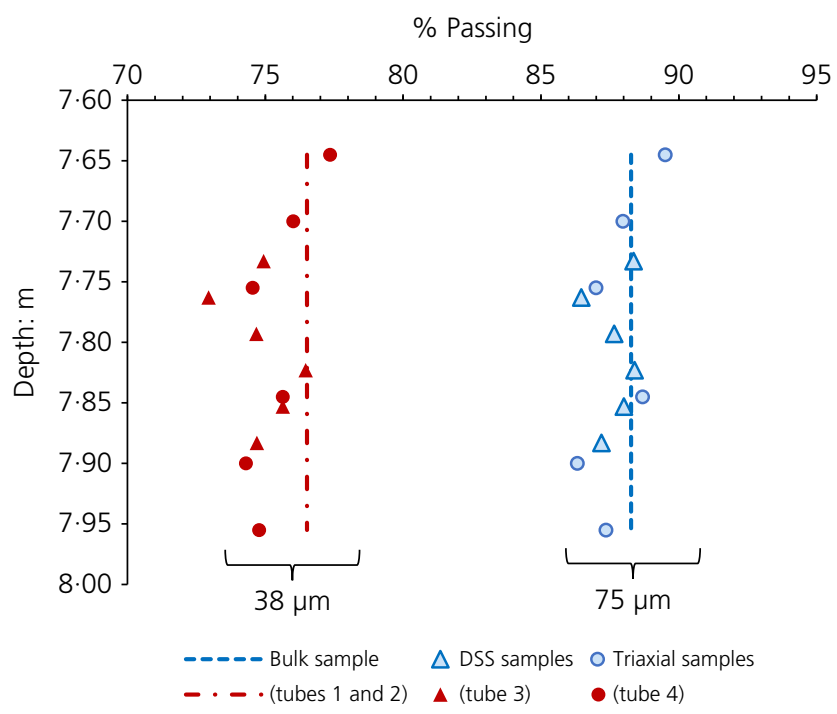

Fig. 7. Gradation variation across sampled depth

laboratory. It is noted that an inability to produce samples as loose in the laboratory as seen in situ for subaqueously deposited silts is not without precedent (Shuttle \& Cunning, 2007).

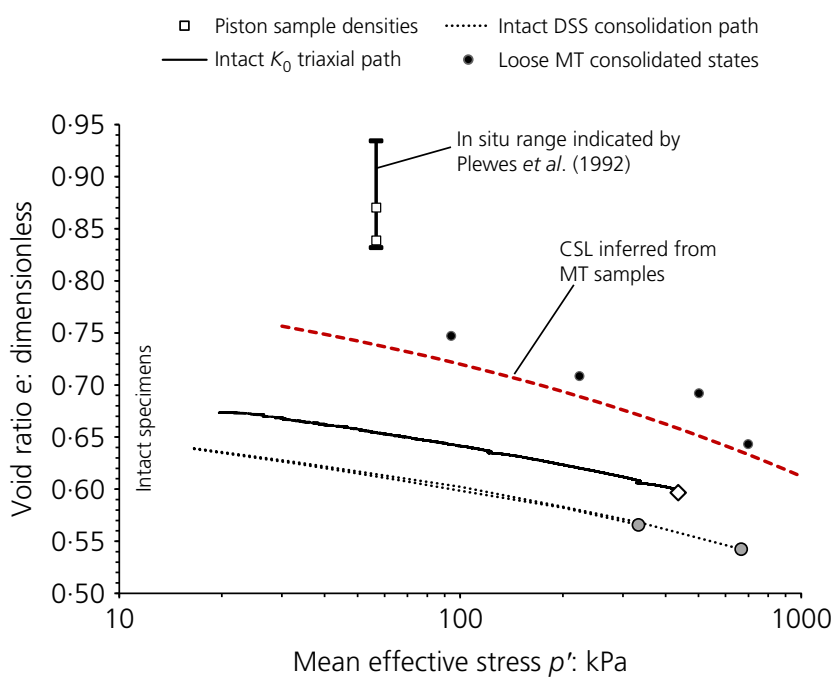

Fig. 8. State diagram - synthesis of laboratory and in situ data

\section{CONCLUSIONS}

$\mathrm{A} \mathrm{CPTu}$ and laboratory characterisation programme of a subaqueously deposited silt tailings indicated (a) good agreement between $\mathrm{CPTu}$ and tube density-inferred state, (b) significant densification of intact specimens, such that use of their results for design would be unsafe - regardless of consolidation stress selected, (c) an inability to prepare reconstituted specimens as loose as in situ conditions and (d) reasonable agreement between the CSL obtained by testing loose MT samples and the behaviour of intact specimens. This final outcome differs from most published comparisons of reconstituted and intact testing on silty materials. A contributing factor to this outcome may be the negligible layering observed in situ.

\section{ACKNOWLEDGEMENTS}

We thank the anonymous reviewers for their useful review comments, which improved the clarity of the paper.

\section{REFERENCES}

Baziar, M. H. \& Dobry, R. (1995). Residual strength and large-deformation potential of loose silty sands. J. Geotech. Engng 121, No. 12, 896-906.

Been, K. \& Jefferies, M. G. (1985). A state parameter for sands. Géotechnique 35, No. 2, 99-112, https://doi.org/10.1680/geot. 1985.35.2.99. 
Been, K., Jefferies, M. G. \& Hachey, J. (1992). Discussion: the critical state of sands. Géotechnique 42, No. 4, 655-663, https://doi.org/10.1680/geot.1992.42.4.655.

Chang, N. (2009). The effect of fabric on the behaviour of gold tailings. $\mathrm{PhD}$ thesis, University of Pretoria, Pretoria, South Africa.

Chang, N., Heymann, G. \& Clayton, C. (2011). The effect of fabric on the behaviour of gold tailings. Géotechnique 61, No. 3, 187-197, https://doi.org/10.1680/geot.9.P.066.

Davies, M. P. (2002). Tailings impoundment failures: are geotechnical engineers listening? Geotech. News 20, No. 3, 31-36.

Desrues, J., Chambon, R., Mokni, M. \& Mazerolle, F. (1996). Void ratio evolution inside shear bands in triaxial sand specimens studied by computed tomography. Géotechnique 46, No. 3, 529-546, https://doi.org/10.1680/geot.1996.46.3.529.

Høeg, K., Dyvik, R. \& Sandbækken, G. (2000). Strength of undisturbed versus reconstituted silt and silty sand specimens. J. Geotech. Geoenviron. Engng 126, No. 7, 606-617.

Jamiolkowski, M. (2014). Sixth J.K. Mitchell lecture - role of in situ testing in geotechnical characterization of copper tailings. Proceedings of the $3 r d$ international symposium on cone penetration testing (CPT'14), Las Vegas, NV, USA.

Jefferies, M. G. \& Been, K. (2015). Soil liquefaction: a critical state approach, 2nd edn. Boca Raton, FL, USA: CRC Press.

Ladd, R. (1978). Preparing test specimens using undercompaction. Geotech. Test. J. 1, No. 1, 16-23.

Morgenstern, N. R., Vick, S. G., Watts, B. D. \& Viotti, C. (2016). Fundão tailings dam review panel. Report on the immediate causes of the failure of the Fundão Dam. New York, NY, USA: Cleary Gottlieb Steen \& Hamilton LLP.
Plewes, H. D., Davies, M. P. \& Jefferies, M. G. (1992). CPT based screening procedure for evaluation liquefaction susceptibility. Proceedings of the 45th Canadian geotechnical conference, Toronto, ON, Canada, pp. 41-49.

Reid, D. \& Jefferies, M. (2017). State parameter as a geological principle in tailings. In Tailings and mine waste 2017 (eds G. W. Wilson, D. C. Sego and N. A. Beier), pp. 305-314. Edmonton, AB, Canada: University of Alberta Geotechnical Center.

Riemer, M. F. \& Seed, R. B. (1997). Factors affecting apparent position of steady-state line. J. Geotech. Geoenviron. Engng 123, No. 3, 281-288.

Robertson, A. M. (2011). Mine waste management in the 21st century - challenges and solutions beyond incremental changes. In Proceedings tailings and mine waste 2011. Vancouver, BC, Canada: Norman B. Keevil Institute of Mining Engineering.

Shelbourn, M. (2010). Geotechnical design verification and performance assessment of tailings storage facilities. In Proceedings of the first international seminar on the reduction of risk in the management of tailings and mine waste (eds A. B. Fourie and R. Jewell), pp. 3-14. Perth, Australia: Australian Centre for Geomechanics.

Shuttle, D. A. (2006). Can the effect of sand fabric on plastic hardening be determined using a self-bored pressuremeter? Can. Geotech. J. 43, No. 7, 659-673.

Shuttle, D. A. \& Cunning, J. (2007). Liquefaction potential of silts from CPTu. Can. Geotech. J. 44, No. 1, 1-19.

Shuttle, D. \& Jefferies, M. (2016). Determining silt state from CPTu. Geotech. Res. 3, No. 3, 90-118, https://doi.org/10.1680/ jgere.16.00008.

\section{HOW CAN YOU CONTRIBUTE?}

To discuss this paper, please submit up to 500 words to the editor at journals@ice.org.uk. Your contribution will be forwarded to the author(s) for a reply and, if considered appropriate by the editorial board, it will be published as a discussion in a future issue of the journal. 